\title{
DRIVING STRESSES IN THE ANTARCTIC ICE SHEET
}

\author{
by
}

\author{
A. P. R. Cooper, N. F. Mclntyre and G. de Q. Robin
}

(Scott Polar Research Institute, University of Cambridge, Cambridge CB2 1ER, England)

\section{ABSTRACT}

Radio echo-soundings obtained during joint programmes of the US National Science Foundation (NSF), the Scott Polar Research Institute (SPRI), and the Technical University of Denmark (TUD) have provided sufficient data of good quality to map driving stress over approximately one half of the Antarctic ice sheet. Computerized averaging of data over 1 degree of latitude squares has largely eliminated local effects of longitudinal stress variations on surface slope. Methods of data handling are outlined. Variations in driving stresses between different regions are discussed in relation to the balancing restraining forces. These are primarily related to ice velocity and thickness, bedrock topography, the presence of basal water and possibly to the development of easy-glide fabric in the ice mass, to the temperature of basal ice layers, and to the excess hydrostatic pressure in areas where ice rests on bedrock well below sea-level.

\section{SOURCES OF DATA AND METHOD OF COMPUTATION}

\section{Sources of dat}

Three sources of data are used in this study. (1) Data from radio echo-sounding (RES) studies, controlled by inertial navigation and carried out by SPRI since 1971 under the joint NSF-SPRI-TUD programme. This provided the bulk of the data used. A $50 \mathrm{~km}$ grid of flight lines was flown over most of the area, with good bedrock coverage. (2) Selected data obtained by seismic sounding on over-snow traverses. (3) Data from Tropical Wind, Energy Conversion and Reference Level Experiment (TWERLE) balloons (Levanon and others 1977) on surface elevations which gave additional coverage, enabling estimates of surface slope to be made in areas where RES data are 1 imited.

Method of computation

The term "driving stress" rather than basal shear stress has been used to indicate that we are mapping the mean driving stresses which are in balance with variable basal shear stresses and longitudinal stress gradients. Robin (1967) and Budd (1968) suggest that jongitudinal stress gradients are unimportant when smoothed over great distances, i.e. above 10 or 20 times the ice thickness. The area under consideration was divided into an overlapping set of rectangles, each being 1 degree of latitude square $(111 \mathrm{~km} \times 111 \mathrm{~km})$ with $25 \mathrm{~km}$ displacement between the centres of successive rectangles. The surface elevation data within each rectangle were used to define a plane, using a multiple finear regression technique. The maximum slope and direction of dip were then calculated from the equation of the plane. The mean of the thickness measurements within the rectangle was taken, or, if none was available for that rectangle, the last computed average thickness was used. The driving stress was then calculated according to the equation

$$
\tau=\rho \cdot g \cdot h \cdot \sin (\alpha),
$$

where $\tau$ is the driving stress, $\rho$ the density of ice, $g$ the acceleration due to gravity, $h$ the thickness of the ice, and $\alpha$ the surface slope. Contour maps of the driving stress were then drawn, using a simple contour plotting program, followed by minor smoothing (Figs.1 and 2). Arrows indicating the direction of maximum slope were also derived by the program, allowing the compilation of flow-line maps, thus providing a check on the consistency of the surface slope. A consequence of the grid size is that the plotted data stop $50 \mathrm{~km}$ from the coast. Furthermore, some detail is lost for the West Antarctic ice streams.

Errors

Surface elevations of the ice sheet are the main source of error. In certain areas, notably northern Victoria Land, frequent changes of aircraft altitude caused significant errors. Results from these areas have not been included in Figures 1 and 2 . The error in the neasurement of the surface elevation is $\pm 30 \mathrm{~m}$ (Drewry 1975) for RES measurements, and about $\pm 60 \mathrm{~m}$ for TWERLE data (Levanon and others 1977). For an error of $+30 \mathrm{~m}$ on one side of a grid square, and $-30 \mathrm{~m}$ on the other, the error would be $\pm 5 \mathrm{kPa}(0.05 \mathrm{bar}) 1000 \mathrm{~m}^{-1}$ of ice thickness. Irregularities in the plotted values and the flow direction suggest that the error is usually less than $10 \mathrm{kPa}(0.1$ bar $)$. Contours in Figures 1 and 2 therefore indicate real variations of driving stress.

\section{ANALYSIS AND DISCUSSION}

A number of patterns nay be identified from Figures 1 and 2. Reference to surface and bedrock contour maps in Drewry and others (1981), Jankowski and Drewry (1981), and Drewry and Steed (in press), will assist. These patterns provide more detailed evidence for testing theoretical concepts than earlier studies (Budd and others 1971, Rose 1978). The most important trend is the increase in driving stresses from the ice divides $(<20 \mathrm{kPa}(0.2 \mathrm{bar}))$ to the ice-sheet margins (>130 kPa $(1.3$ bar $))$ except where these are bordered by major ice shelves. This trend can be seen in both East and West Antarctica, a) though there are two inportant differences between these areas; firstly, the rate of increase with distance in West Antarctica is notably greater than in East Antarctica, and, secondly, the highest values in West Antarctica are consistently less than those in East Antarctica. The pattern of driving stresses 


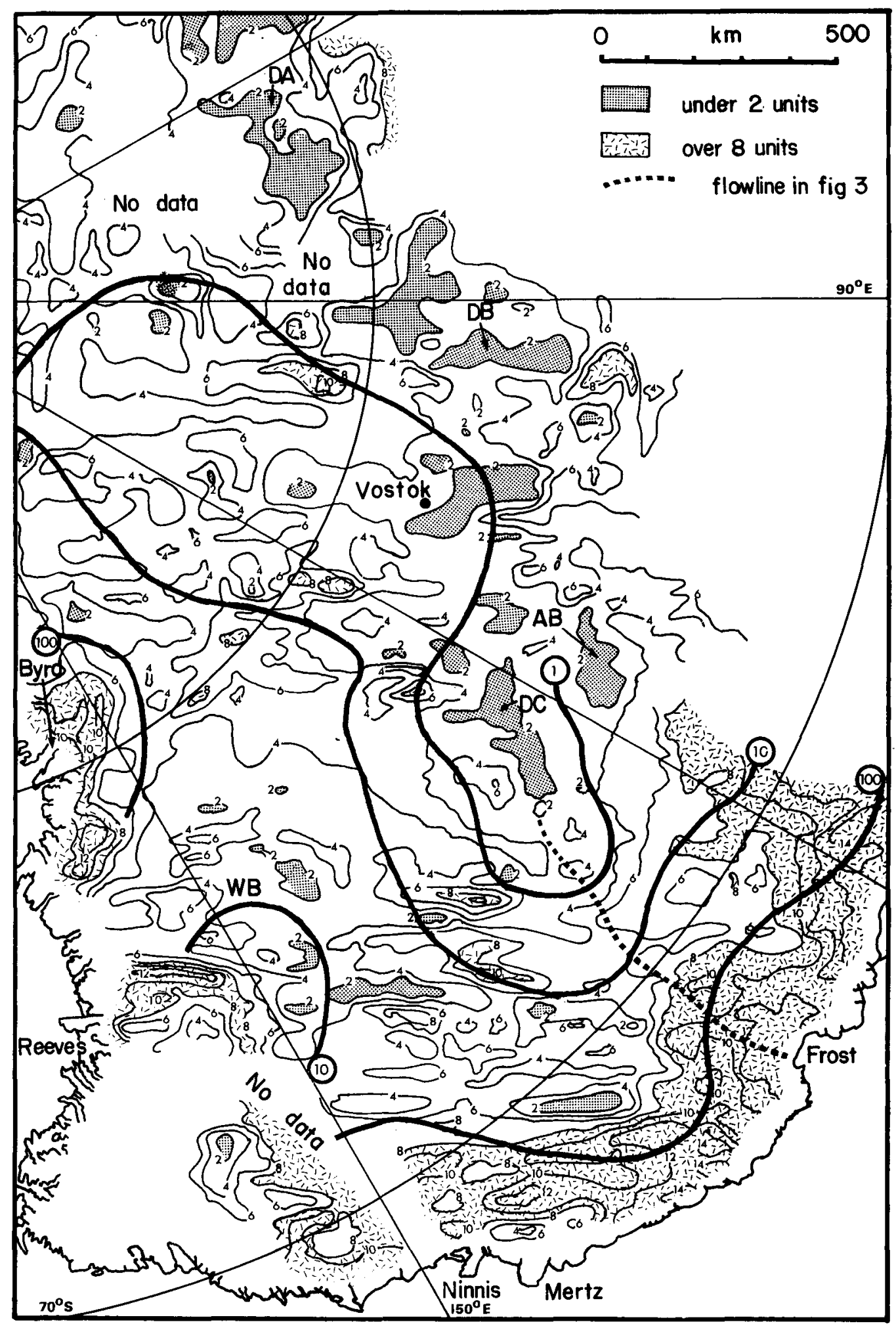

Fig.1. Driving stresses (thin contours) and mean shear strain-rates (bold contours) in East Antarctica. Units at $10 \mathrm{kPa}(0.1 \mathrm{bar})$ and $1.0 \times 10^{-4} \mathrm{a}^{-1}$ respectively. Driving stresses under $20 \mathrm{kPa}(0.2 \mathrm{bar})$ are stippled and those over $80 \mathrm{kPa}(0.8 \mathrm{bar})$ are hatched. DA: Dome $\mathrm{A}$, $\mathrm{DB}$ : Dome B, DC: Dome C, WB: Wilkes basin, AB: "Aurora" basin. 


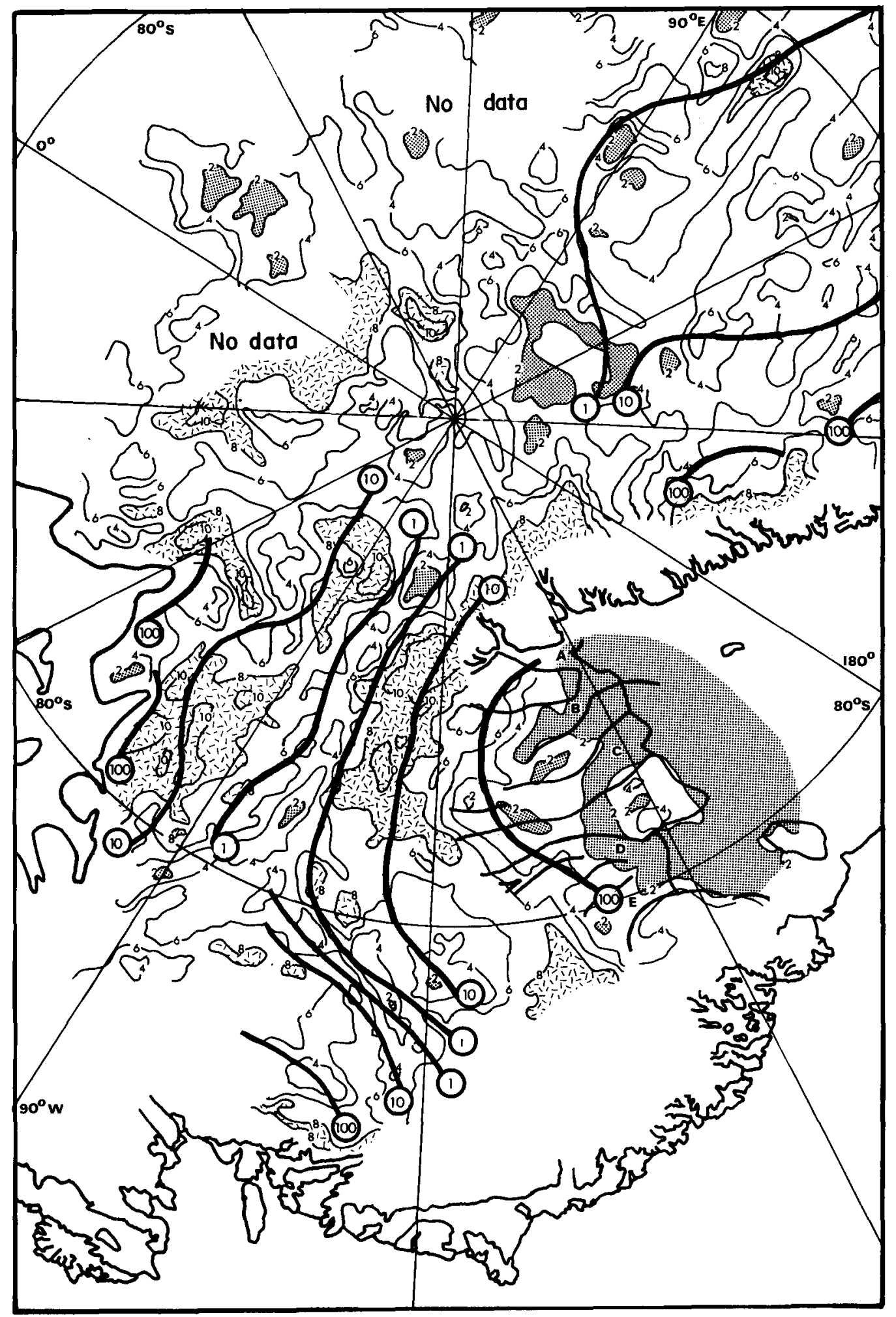

Fig.2. Driving stresses and mean shear strain-rates in West Antarctica. Key as for Figure 1 . A, B,C,D, and $E$ are ice streams flowing into the Ross Ice Shelf. 


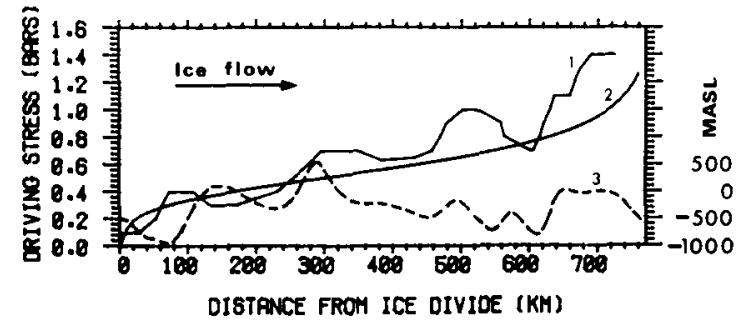

Fig.3. Calculated (1) and theoretical (2) (Vialov 1958) profiles for driving stress between Dome $C$ and Frost Glacier (see Fig.1). Bedrock elevations (m a.s.1.) (3) are also shown.

along one flow line in Wilkes Land is shown in Figure 3 and is compared with that for a theoretical profile of the ice surface on flat bedrock with deformation by internal shear, which gives the surface profile

$$
(h / H)^{2 \cdot 6}+(x / L)^{1 \cdot 3}=1
$$

(Vialor 1958, Paterson 1981), where $h$ is the ice thickness at any point, $H$ the maximum ice thickness, $x$ the distance from the ice divide, and $L$ the distance from the ice divide to the ice margin. It is clear that bedrock irregularities of a few tens of kilometres in extent produce long wavelength variations in driving stress.

At a smaller scale, it is possible to associate characteristic values with certain glaciological circumstances. Thus, low driving stresses (typically less than $20 \mathrm{kPa}(0.2 \mathrm{bar}))$ are often found in the following five situations: (1) at Domes $A, B$, and $C$ (Fig.1), and around ice divides (especially Fig.2) (al though ice velocities are at their lowest here, and are expected to fall to zero if the ice divide has no slope, smoothing has el iminated zero values), (2) in subglacial basins; this can be seen in the Wilkes basin and the tentatively named "Aurora" subglacial basin $\left(69^{\circ} \mathrm{S}, 137^{\circ} \mathrm{E}\right)$, (3) where subglacial "lakes" (Oswald and Robin 1973) of large extent are present, (4) at the seaward ends of the West Antarctic ice streams (Fig.4(b)), and (5) in small areas where effects of longitudinal stress gradients have not been entirely eliminated as discussed below.

High driving stresses of limited extent $(>100 \mathrm{kPa}$ (1 bar)) are found mainly in two situations: firstly, in crescentic zones around the heads of outlet glaciers, that is, in areas of great convergence of flow. This can be seen around Frost and Byrd glaciers and inland of the West Antarctic ice streams; here the proximity of the catchment areas has caused the coalescence of these crescentic high zones. Secondly, we find isolated patches with a high stress. The occurrence of alternate bands of high and low stress oriented across the flow-line direction between $130^{\circ} \mathrm{E}$ and $150^{\circ} \mathrm{E}$ north of $75^{\circ} \mathrm{S}$ (Fig.1), and in Figure 3 , suggests that longitudinal stress gradients caused by bedrock irregularities have not been fully smoothed out by the averaging process, and that such stresses can be transmitted over distances of 50 to $100 \mathrm{~km}$, a somewhat greater distance than suggested earlier.

Single RES flights down flow lines of individual outlet glaciers have also been used to show the patterns of driving stresses. Data have been averaged using a $50 \mathrm{~km}$ window on these lines. The resulting profiles down glaciers and ice streams can be divided into two types. Most outlet glaciers show increasing driving stresses to $150 \mathrm{~km}$ or so from the grounding line. At this point, there is a further increase to a peak around $50 \mathrm{~km}$ from the grounding line before it falls by about $50 \mathrm{kPa}(0.5 \mathrm{bar})$ over the next $25 \mathrm{~km}$ (Fig.4(a)). Glaciers showing this pattern include Reeves, Byrd, Ninnis, and Frost. This is very similar

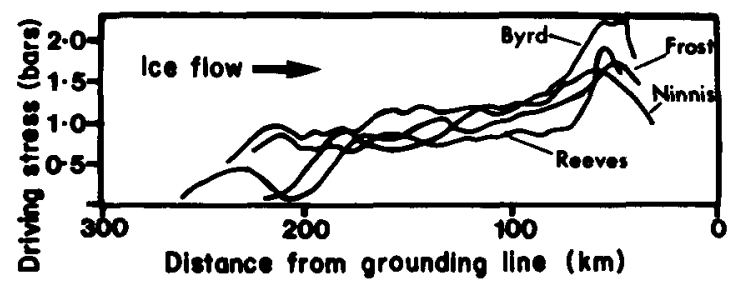

Fig.4(a). Profiles of driving stresses down outlet glaciers in Figure 1.

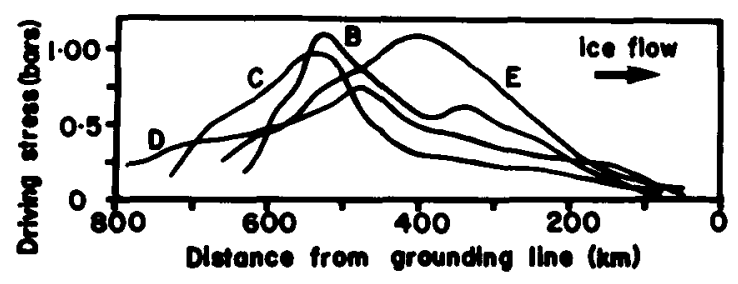

Fig.4(b). Profiles of driving stresses down ice streams $B, C, D$, and $E$ of Figure 2 .

to that found by Budd and Young (1979) along the International Antarctic Glaciological Project (IAGP) flow line in Wilkes Land. Ice entering the West Antarctic ice streams shows increasing driving stresses with distance until some 400 to $550 \mathrm{~km}$ from the grounding line, after which the value falls more gradually than in East Antarctica from a peak of around $100 \mathrm{kPa}(1.0 \mathrm{bar})$ to $20 \mathrm{kPa}(0.2 \mathrm{bar})$ around $150 \mathrm{~km}$ ( $\mathrm{Fig.4(b)).}$

The most important parameters influencing the patterns of driving stress appear to be ice velocity and thickness (Nye 1957, Weertman 1957, Budd and Radok 1971, Budd and Jenssen 1975, Budd and Smith 1981, Young 1981). Mass flux must increase from zero at centres of outflow to high values near the coast; highest values will be found where ice is channelled into ice streams and outlet glaciers. In the absence of appreciable sliding, and if longitudinal stress gradients have been effectively smoothed out, we expect surface velocity to be proportional to some power of the driving stresses and to thickness: thus

$$
V=k \cdot h \cdot \tau^{n}
$$

(Budd and Radok 1971), and hence

$$
V / h=k \cdot \tau^{n},
$$

where $V$ is the ice velocity, and $k$ and $n$ are constants. In addition to driving stresses, Figures 1 and 2 show contours of $V / h$ derived from balance velocities and thickness, a ratio that is proportional to the mean shear strain-rate through the ice thickness. Balance velocities were calculated from the flow lines previously obtained (see above) and from accumulation and thickness data being compiled for the Antarctic glaciological and geophysical folio (Drewry in preparation). The pattern of increase of $\mathrm{V} / \mathrm{h}$ from the ice divides to the continental margins is broadly similar to some power of the driving stress.

However, a zone of low values of $\mathrm{V} / \mathrm{h}$ in the Wilkes basin is apparent. The $1.0 \times 10^{-4} \mathrm{a}^{-1}$ contour encircles the low driving stresses of the ice divides, where velocities are also at their lowest, while the $100 \times 10^{-4} \mathrm{a}^{-1}$ contour is generally associated with driving stresses of over $80 \mathrm{kPa}(0.8 \mathrm{bar})$ and with the zones of convergence of flow and high stresses around the heads of outlet glaciers. Values of $n$ and $k$ in Equation (3) of 3.45 and 0.02225 (Budd and Smith 1981 ) and of 2.50 and 0.08555 (Budd and Jenssen 1975) have been suggested for polar ice. Plotting balance 
velocities calculated from data from Wilkes Land against driving stresses allows an extension of the relationship down to values of $1.0 \times 10^{-4} \mathrm{a}^{-1}$ for $\mathrm{V} / \mathrm{h}$, which gives $n=2.51$ and $k=0.0085$ (Fig.5). Although the scatter for these data is greater than for other sources (the coefficient of correlation $R=0.810$, c.f. $R=0.936$ for Budd and Smi th 1981), the data seem sufficiently consistent to draw the following conclusions. (1) Although our data in Figure 5 refer to balance velocities, like Budd and Smith (1981) we find a closer relationship between

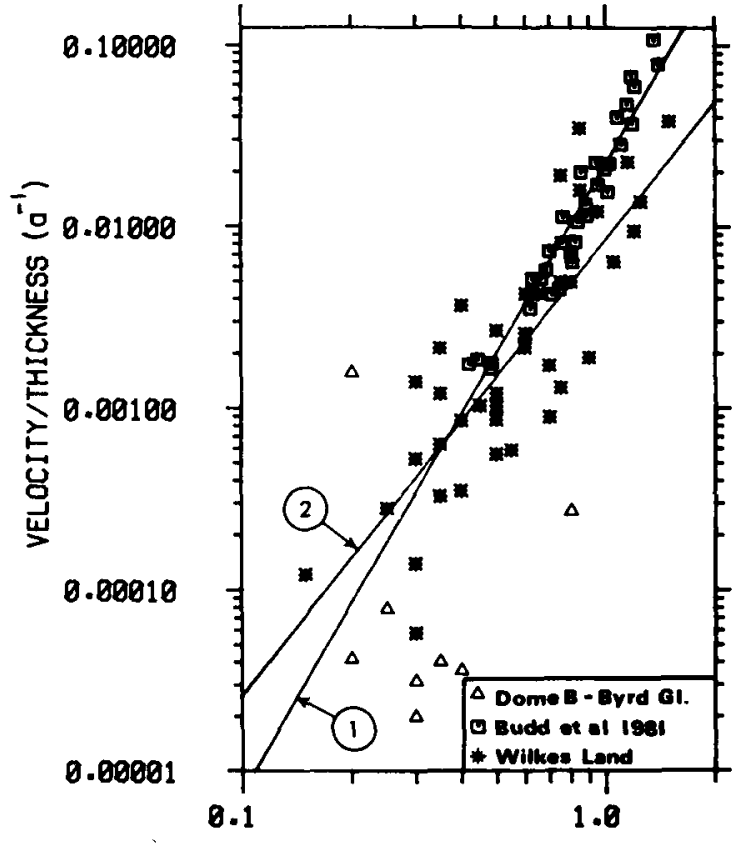

DRIVING STRESS (BRRS)

Fig.5. Variations of mean shear strain-rate $\mathrm{V} / \mathrm{h}$ with driving stress. Data are from Budd and Smith (1981) (regression line 1), Wilkes Land (regression 1 ine 2), and also show points from a Dome C-Byrd Glacier profile.

$\mathrm{V} / \mathrm{h}$ and driving stress than between $\mathrm{V}$ and driving stress. From this we conclude that the major part of surface motion is due to internal shear within the ice mass, not to sliding. (2) The agreement shown in Figure 5 between our steady-state values of $\mathrm{V} / \mathrm{h}$ and with the observed relationship for Equation (3) of Budd and Smith (1981) indicates that balance velocities are correct to a first approximation. (3) The above agreement also indicates that driving stresses are not closely related to ice temperatures over much of the ice sheet. If the temperature of basal layers were all at pressure-melting point, this could explain the observation. However, it seems clear from studies of temperature-depth relationships that many parts of the Antarctic ice sheet with basal temperatures below pressure-melting point still fall on the $\mathrm{V} / \mathrm{h}$-driving stress plot. This could be due to the development of easy-glide fabric in the ice compensating for the colder temperatures that would otherwise require greater driving stresses.

It should be noted that points for the flow line between Dome $B$ and Byrd Glacier on Figure 5 show low values of $V / h$ corresponding to higher values of driving stress than those predicted by the regression lines. Values of driving stress on Figure 1 , near Dome $A$, suggest that the effect may be stili more marked there. In these regions, basal as well as surface temperatures will be low at many points and require high driving stress. Also, near centres of outflow, crystal fabrics favouring easy glide may not be fully developed.

Another obvious factor related to driving stress is the effect of basal water. On the macroscopic scale, this is readily shown at the sub-ice lake near Vostok described in Robin and others (1977). This lake is estimated to be $\sim 150 \mathrm{~km} \times 50 \mathrm{~km}$, with a few grounding points of limited extent only. We see in Figure 1 that values of driving stress fall to under 0.2 bar over the region of the lake $\left(77.5^{\circ} \mathrm{S}, 104^{\circ} \mathrm{E}\right)$. other sub-ice lakes described in that paper are small in extent compared to the smoothing used for analysis, so while they may cause some of the abnormally low values shown in individual squares, they will not generally have a major effect on driving stress.

Sub-ice water may also have an important effect under major ice streams and outlet glaciers, where low driving stresses are explained by the presence of subglacial water of considerable extent. Owing to its depth below sea-level, this is at an even greater hydrostatic pressure than elsewhere, and so reduces bottom drag by carrying a high proportion of the weight of the overlying ice.

On both the macroscopic and smaller scales, bedrock roughness generally appears to have little effect on driving stress, presumably because most deformation in the ice mass is taking place above the level of bedrock relief (Robin and Millar 1982). on the smaller scale, longitudinal and basal shearstress gradients in the flow direction do have a large effect on local surface slopes, al though not on ice velocity. There are, however, certain areas, such as the northern parts of the Wilkes and "Aurora" subglacial basins where the driving stress appears abnormally low. While the great ice thickness in these basins will cause some lowering of velocity for the same steady-state mass flux, some additional effect, such as a smooth bedrock, may be necessary to explain the low driving stresses observed since there are no obvious signs of large subglacial lakes.

The geometry of basins leading to major outlet glaciers shows a common pattern of distribution of stress. The region of highest stress lies on a rough arc centred on the head of the outlet glacier. This is shown most clearly for the largest glaciers, such as Byrd and Frost, but our grid size is too large to see the effect on smaller glaciers, al though contour maps suggest that it is present. However it does appear that the larger the outlet glacier, (that is, the larger the mass flux involved), the larger is the radius of the arc of highest stress. This suggests that this radius will vary in response to changes of mass flux through an individual outlet glacier. Such changes should be taken into account when modelling the flow and possible instabilities of polar ice sheets.

The observed gradual fall of driving stress from $i$ ts maximum value to the grounding line on ice streams shown in Figure 4(b) should also be noted. The peak driving stress is again similar to that reached before a surge of a temperate glacier, but this could be a stable feature in the ice streams, as it is repeated in four cases. This may indicate that the sliding of cold polar glaciers with the base at melting point differs from the behaviour of temperate glaciers approaching a critical sliding velocity.

\section{ACKNOWL EDGEMENTS}

We acknowledge the considerable help of many organizations and individuals with this programme, especially the US National Science Foundation, who sponsored and guided the work, the US Navy Squadron $V \times 6$, whose aircrews made the flying programme so successfuT, and the UK Matural Environment Research Council for their considerable research grants and studentships for the UK contributions to the programme. 
REFERENCES

Budd WF 1968 The longitudinal velocity profile of large ice masses. International Association of Scientific Hydrology Publication 79 (ceneral Assembly of Berm 1967 - Snow and Ice): 58-77 Budd W F, Jenssen D 1975 Numerical modelling of glacier systems. International Association of Hydrological Sciences Publication 104 (General Assembly of Moscow 1971 - Snow and Ice): 257-291

Budd W F, Radok U 1971 Glaciers and other large ice masses. Reports on Progress in Physics 34(1)

Budd W F, Smith I N 1981 The growth and retreat of ice sheets in response to orbital radiation changes. International Association of Hydrological Sciences Publication. 131 (Symposium at Canberra 1979 - Sea level, ice and climatic change: 369409

Budd W F, Young N W 1979 Results from the I.A.G.P. flow-line study inland of Casey, Wilkes Land, Antarctica. Journal of Glaciology 24(90): 89-101

Budd W F, Jenssen D, Radok U 1971 Derived physical characteristics of the Antarctic ice sheet. ANARE Interim Reports Ser A (IV) Glaciology (Publication 120)

Drewry D J 1975 Radio echo sounding map of Antarctica, $\left(\sim 90^{\circ} \mathrm{E}-180^{\circ}\right)$. Polar Record 17(109): 359-374

Drewry D J, Steed R H N In press. Geophysical investigations of the northern margin of the Wilkes sub-glacial basin, adjacent terrain and associations with southern Australia. In Craddock C (ed) Proceedings Third Symposium on Antaretic Geology and Geophysics, Madison, Wisconsin, 1977

Jankowski E J, Drewry D J 1981 The structure of West Antarctica from geophysical studies. Nature 291(5810): 17-21

Levanon N, Julian P R, Suomi VE 1977 Antarctic topography from balioons. Nature 268(5620): 514516

Nye J F 1957 The motion of ice sheets and glaciers. Journal of Glaciology 3(26): 493-507

Oswald G K A Robin G de 01973 Lakes beneath the Antarctic ice sheet. Nature 245(5423): 251-254

Paterson W S B 1981 The physics of glaciers. Second edition. Oxford, Pergamon Press

Rob in $G$ de $Q 1967$ Surface topography of ice sheets. Nature 215(5105): 1029-1032

Robin G de Q, Millar D H M 1982 Flow of ice sheets in the vicinity of subglacial peaks. Annals of Glaciology 3: 290-294

Rob in G de Q, Drewry D J, Meldrum D T 1977 International studies of ice sheet and bedrock. Philosophical Transactions of the Royal Society of London Ser B 279(963): 185-196

Rose K E Unpublished. Radio echo studies of Marie Byrd Land, Antarctica. (PhD thesis, University of Cambridge 1978)

Vialov S S 1958 Regularities of glacial shields movement and the theory of plastic viscous flow. International Association of Scientific Hydrology Publication 47 (Symposium of Chamonix - Physics of the Motion of Ice): 266-275

Weertman $\mathrm{J} 1957$ On the sliding of glaciers. Journal of Glaciology 3(21): 33-38

Young N W 1981 Responses of ice sheets to environmental changes. Intermational Association of Hydrological Sciences Publication 131 (Sympos ium at Canberra 1979 - Sea level, ice and climatic change) $331-360$ 